\title{
How a Google Grant and Google Analytics Improved a Website: A Case Example of a University's Arbitration and Mediation Website Used by Students, Business and the Public
}

\author{
Kaitlyn Andrykovich ${ }^{1}$, Emily Wisniewski ${ }^{2} \&$ Maris Stella (Star) Swift ${ }^{2}$ \\ ${ }^{1}$ Customer Marketing and Emerging Technology Department, Meijer, USA \\ ${ }^{2}$ Grand Valley State University, Allendale, USA \\ Correspondence: Maris Stella (Star) Swift, Associate Professor of Law, Grand Valley State University, Allendale, \\ Michigan, USA. E-mail: swiftgvsu@gmail.com
}

Received: May 2, 2014

doi:10.5430/ijba.v5n4p60
Accepted: June 24, $2014 \quad$ Online Published: July 4, 2014

URL: http://dx.doi.org/10.5430/ijba.v5n4p60

\begin{abstract}
The purpose of this paper is to describe the Grand Valley State University Arbitration and Mediation Website and to explain how web site analytics provided by Google helped redefine and reshape this website so that it was easier to use and delivered better content for users all over the globe.

The web site's focus is on two common forms of alternative dispute resolution, arbitration and mediation. The web site is currently used as both a free resource for arbitration awards and as a teaching tool for these two popular alternative dispute resolution methods. Mediation and arbitration have become the chosen method of dispute resolution in business so the need for more information about these topics is timely.

The Websites are aided by a Google Grant that has provided the administrators with an unprecedented amount of data relating to its usage and users. This data has allowed the administrators to change and adapt the website in the goal of making it more user-friendly and ultimately a teaching aid.

The primary purpose of the team that administers the arbitration web site (and other web sites and mobile applications) is to teach through technology as a public service of the university.

The site is used by many in business and the public in general all over the globe.

Keywords: arbitration, education, technology, web sites, web sites as texbooks, third world education, internet education, free text, free education web sources, student websites, class websites, higher education web sites, employment law, ADR, labor law, mediation
\end{abstract}

\section{Introduction}

\subsection{Introduction of the Issue}

In 2007, a professor who was well versed in the world of collective bargaining developed a website through Grand Valley State University to provide free arbitration awards (decision) to the public. Additionally, the website included information about the arbitration process, the mediation process and detailed instructions on how to conduct mediations and arbitrations. A Google AdWords grant aided with increasing website traffic to the site. The Google grant was originally awarded in 2008 and provided $\$ 10,000$ per month of in-kind Google AdWords (Note 1) to advertise for the websites. In 2013, the AdWords grant was raised by Google to $\$ 40,000$ per month. (Note 1)

\subsection{Introduction of the Team}

Due to the enormity of this large grant, the professor recruited several students to assist her with the project whom she nicknamed Team Web GVSU (In this paper the group may be referred to as "the team" or "Team Web"). Since Team Web is composed of under-graduate, graduate college students and alumni much of the work is self-directed. The team usually convenes once a week to discuss problems and divide up projects that need to be accomplished. Furthermore, at these meetings they review analytics on the website to ensure the ad campaigns are functioning properly. Many of the students separate themselves into pairs to accomplish select tasks laid out for them; which results in students meeting in smaller groups throughout the wee and from different locations depending on the time 
of year. Two forms of technology that permit the Team to seamlessly complete projects from remote locations are Dropbox (a cloud) (Note 3) and ooVoo (video chat and desk top sharing). (Note 4)

\section{Projects}

Team Web operates three websites: the Arbitration and Mediation website, The Digital Workplace website(Note 5) and the Negotiation website. (Note 6) The websites are under the Grand Valley State University domain, but the content and editing is maintained by the students and advisors of Team Web. The Mediation and Arbitration website supplies free information regarding both processes. This information includes guidance on how to prepare for these procedures, step by step instructions, key definitions, examples of real arbitration awards and resumes for arbitrators. The material is provided in a variety of formats ranging from text to videos to short presentations. In tandem with the website, similar information is provided on an android app (Note 7) that is available for free from the Google Play Store.

The next section will briefly explain the content of the web site. We hope this review will give the reader an idea of the complexity of the site and summarize the large amount of data provided for site users as a public service of the university.

\subsection{Arbitration and Mediation}

Mediation is one type of dispute resolution. In this process two parties, who are involved in a dispute, go before a neutral individual. This third party individual is mutually selected by both the parties and is referred to as the mediator. The mediation process commences with an informal mediation hearing, where both parties work towards an agreement. The mediation hearing can occur with both parties present and working together or the mediation can use a technique called shuttle diplomacy. Shuttle diplomacy involves the mediator going back and forth between parties with proposals and counterproposals until an agreement is reached. (Note 8) When both parties have agreed upon a satisfactory outcome they often sign a settlement agreement. The process of mediation has several benefits over litigation and other alternative dispute resolution processes. This is because it is a quicker procedure, less costly and finally, the parties have more control over the final agreement since they often co-write the mediation agreement that resolves the dispute. (Note 9)

Arbitration is a dispute resolution method where two parties who are in disagreement go before an arbitrator rather than going to court. (Note 10) Similar to the mediator, the arbitrator is a neutral third party, mutually selected by the disputing parties, who will preside over the arbitration process and resolve the dispute. There are three main types of arbitration commonly used in the United States: grievance arbitration, interest arbitration and arbitration of statutory disputes. (Note 11) Grievance arbitration is specifically mentioned in a contract between employers and unions. If a union or employer suspects the labor contract has been violated a grievance is filed and the case (depending on the steps of the grievance process) is heard by a neutral arbitrator. Interest arbitration is used when the parties cannot settle a contract so they use an interest arbitrator to make the contract for the parties. (Note 12) Finally, arbitration of statutory disputes is used with non- unionized contract agreements. The employers have their employees sign a contract stating that both parties will use arbitration rather than litigation to solve disputes involving employment. Decisions made by an arbitrator, regardless of the type of arbitration, are typically binding and will not be overturned by a court of law. (Note 13)

\subsection{Content of the Arbitration and Mediation Websites}

There are several steps to any arbitration process and these are all covered by the web site. In addition there are numerous arbitration decisions on the web site that are summarized and the decisions are also available in total on the site.

To provide clarity the web site carefully explains the arbitration process through diagrams, notes and videos. (Note 14) Yet the question for the team is always how well is the web site doing and are the changes truly improvements? Before the team had access to the data from Google they guessed or asked students who were using the web site for classes. The next section of the paper will explain how the team now uses Google Adwords and Analytics as a key data point to understand the site's web users and the popularity of the various pages of the site.

\section{Impact of Google Analytics on the Website}

As stated previously, the large grant from Google and the vast amount of data provided by Google about the web site and its ads campaigns eventually required the team to take into account more than simply the sites content. As the team became more conversant with Google Analytics they began to comprehend that web sites using Google 
Adwords receive mountains of data and this data imparts a great deal of information, not only about the web site, but also about the users of the web site.

\subsection{Tasks of Team Web Dealing with Analytics}

On any given day Team Web can look to see where in the world users are reading the website, how long they are on the site and what aspects of the site keep them most engaged. This knowledge has led the team to think about how the Google Analytics could improve the web site by concentrating on the actions of the web site users.

When the team looked at a map and saw that one of the main users of the site was South Africa they were not surprised because this country is known for favoring dispute resolution methods like mediation and arbitration. (Note 15) Yet when the team saw that many other countries were using the site they decided that the site needed to be cleaner and more concise in the presentation of ideas and concepts so that anyone from any country could read and listen to the site regardless of nationality.

\subsection{Impact of Learning Styles on the Website}

The team also started to think about the different types of learners who may use the site. The analytics from Google showed that while some found a section of the website fascinating others jumped off the site immediately. The team did not know why this happened but they began to have discussions about the idea of appealing to more than one learning style on the site. For example, most of us are aware that different individuals process and learn information in different ways. (Note 16) In fact "if the way the material is presented corresponds to a person's natural learning style then learning the material becomes easier and more enjoyable." (Note 17) Because of this fact, educators have to be aware of how they can present information in a variety of ways in order to enhance the learning process for differing learning styles. The Google analytics pushed the team to think about these different learning styles and the team strove to present the material in several different formats as a consequence.

Team Web's response to the analytics reflects the Flemings VARK model which acknowledges that if you are going to teach well you must present the subject matter in different ways for different learning styles. (Note 18) The VARK model divides learning styles into four different groups- Visuals, Aural, Read/Writers and Kinesthetic. (Note 19) Visual learners process information best through seeing visual representation of it; for this group of learners we have presentations and flow charts of the information. (Note 20) Aural learners best process information heard by ear, for these learners the site has provided videos with audio. (Note 21) Reader/Writer learners use reading and writing to process the information. For this type learner the team provided a large amount of text on various complex topics. (Note 22) Finally, the last style is Kinesthetic learners who gain knowledge through experience. For this type learner the team provided materials for them to recreate a mock arbitration or mediation. (Note 23)

It is fair to say the team was fortunate to have the data and analytics from Google to re-think the web site content and the various learning styles of the sites users. (Note 24) Yet these revelations only occurred because the team was the recipient of a Google Grant. In the next section we will briefly explain the grant.

\section{The Google Grant}

\subsection{About Google Grants}

In 2008, because of the site's usage, purpose, and strong potential for growth, Google awarded Team Web a Google Adwords grant with a monthly allowance of $\$ 10,000$. With this grant no money is actually exchanged, instead the funding is received through the use of free click- through ads from Google. (Note 25) The grant is used to create short ads for the web that direct anyone who clicks on the ads to the web site. These ads show along the top and side of Google search engine results, the grant money is then used when someone clicks on an ad within a Google search. With a Google grant the maximum cost of a user clicking on an ad is two dollars. (Note 26)

\subsection{Impact of Google Grant on Team Web}

Through increased exposure, the grant creates a means for Team Web to reach users all over the world. The ads therefore give Team Web the opportunity to implement their bifurcated purpose of providing a free arbitration-teaching platform and a robust database. In November 2012, after reviewing the success of the websites and apps Google raised Team Web's grant to Google Pro status. (Note 27) The success of the site was determined by site usage and the fact that people from all over the world were accessing the resources provided by Team Web. (Note 28) This grant awarded Team Web a $\$ 40,000$ monthly AdWords allowance.

In addition to providing free web based ads that generate exposure to the webpages, the Google grant also provides the tools needed to track what happens when users click on those ads. The following section will provide a basic introduction to Google Analytics, defining key terms to provide a better understanding of both the significance and 
use of Google Analytics. It is important for the reader to understand that by grasping the basic concepts of Google Analytics, they can better understand how these data tools aid Team Web in their quest to continually improve the web site. Each term provides a wealth of knowledge about the data that is collected by Google and provided to the grant holder.

\section{The Basics of Google Analytics}

Google Analytics is the main source of data management used by Team Web. Analytics are provided for the website and the ad campaigns. Each individual ad has reports for its own analytics. It is through Google Analytics that Team Web is able to gain an understanding of the audience interfacing with the resources that Team Web provides. As a result of analyzing the quantitative data provided by Google Analytics, Team Web is able to alter the web pages to best fit consumer preferences.

5.1 Key Terms That Everyone with a Website Must Know (Note 29):

- Google AdWords: The Google provided program, used for managing Ad Campaigns and creating Ads. (Note 30)

- Google Ad Campaign: A division within a Google Adwords account. Each campaign can be allocated a specific dollar amount and can be targeted towards a specific geographic region. (Note 31)

- Google AdGroup: A group of similar ads all connected to the same list of keywords, an AdGroup is made within an Ad Campaign. (Note 32)

- Impressions: The number of Google searches that the ad created has appeared in. (Note 33)

- Clicks: The number of clicks the Google Ad has received. (Note 34)

- Cost Per Click: The cost associated by a click on a Google Ad. (Note 35)

- Click Through Rate: Ratio of how many people click on your advertisement divided by the number of views the ad had (impressions). Clicks/Impressions. (Note 36)

Some other important terms to know in order to understand Google Analytics are as follows:

- Bounce Rate: Percentage amount given to single page visits or visits in which the person left your site from the entrance (landing) page. (Google AdWords) (Note 37)

- Average Visit Duration: The average amount of time spent on webpage. (Note 38)

- Keywords: The search term used when people use a Google search engine. (Note 39)

- In Page Analytics: Breakdown of the webpage, displaying what areas are getting the most clicks. (Note 40)

\subsection{Evolving Focus to Improve Website and Better Utilize Google Grant}

In July 2013, after coming to the realization that the bounce rates for the ads and webpages were high while visit duration on the webpage was low (Note 41), Team Web shifted their focus from clicks and visits to user interactions. This change in direction included the following:

- redesigning the AdWords account organization (Note 42)

- reallocation of the grant money (Note 43)

- tailoring each keyword (Note 44)

- making ads more specific to the portion of the website that they are forwarded to (Note 45)

- adding resources to the webpages, such as videos (Note 46), worksheets, and diagrams, providing multiple platforms to learning a specific portion of arbitration or mediation

\subsection{The Global Impact of Our Website}

Figure 1 displays the global impact of the Arbitration site. The table provides a comparison between two 8-week periods (Note 47) in 2013. The time period between Feb.24, 2013 and Apr. 20, 2013 represents the time prior to the changes made by Team Web. The time period between Oct.13 and Dec 7, 2013 is the 8-week period during which a majority of the changes had already been made. Videos and other design factors were implemented during this time. In both time frames, a majority of visits come from the US, India, United Kingdom, and Canada. Yet Google data indicates that people from all over the world were accessing the site during both time periods. 
Figure 1 shows a detailed report of the data changes between period 1 and 2, representing the impact that the changes to the site made. As shown, visits in period 2 increased substantially, pages per visit also increased, while bounce rates dropped.

\begin{tabular}{|c|c|c|c|}
\hline \multicolumn{4}{|c|}{ United States } \\
\hline & Visits & Pgs. per visit & Bounce Rate $\%$ \\
\hline Period 1 & 1681 & 2.37 & 59.61 \\
\hline Period 2 & 4033 & 2.92 & 55.53 \\
\hline \multicolumn{4}{|c|}{ India } \\
\hline & Visits & Pgs. per visit & Bounce Rate $\%$ \\
\hline Period 1 & 740 & 1.24 & 87.70 \\
\hline Period 2 & 3367 & 1.69 & 70.95 \\
\hline \multicolumn{4}{|c|}{ United Kingdom } \\
\hline & Visits & Pgs. per visit & Bounce Rate \% \\
\hline Period 1 & 70 & 1.23 & 85.71 \\
\hline Period 2 & 1270 & 1.70 & 70.94 \\
\hline
\end{tabular}

Figure 1. Geographic breakdown

\subsection{Bounce Rate}

Figures 2 and 3 below represent the change in bounce rate between the two points of reference. (Note 48) As a result of their change in focus, Team Web began to use bounce rate as a way of measuring site interaction. A visitor will usually bounce from a site when he or she realizes that the site does not offer the information that they were seeking or had been led to believe would be found there by an earlier page or link. (Note 49) With this understanding GVSU Team Web aimed to lower the bounce rate by implementing the changes mentioned previously. The first step to be taken was deciding a target bounce rate. Deciding a target bounce rate can be a difficult task mainly because not all bounces are bad. If a visitor leaves the page they entered on, it may just mean that they found the information that they needed. Team Web made it their goal to keep their bounce rate around 60\%. (Note 50) As shown in Figure 3, before the changes were made the bounce rate for the 8 -week period was near $80 \%$ with 4,733 visitors. As shown in Figure 4 , after the changes the bounce rate dropped to near $65 \%$ while visits rose to 15,332 . 


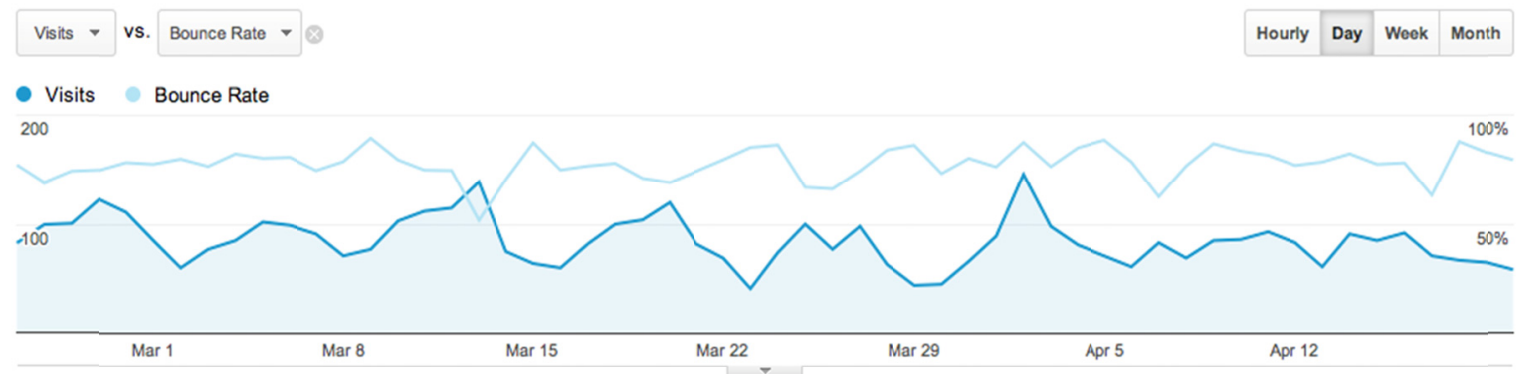

3,848 people visited this site
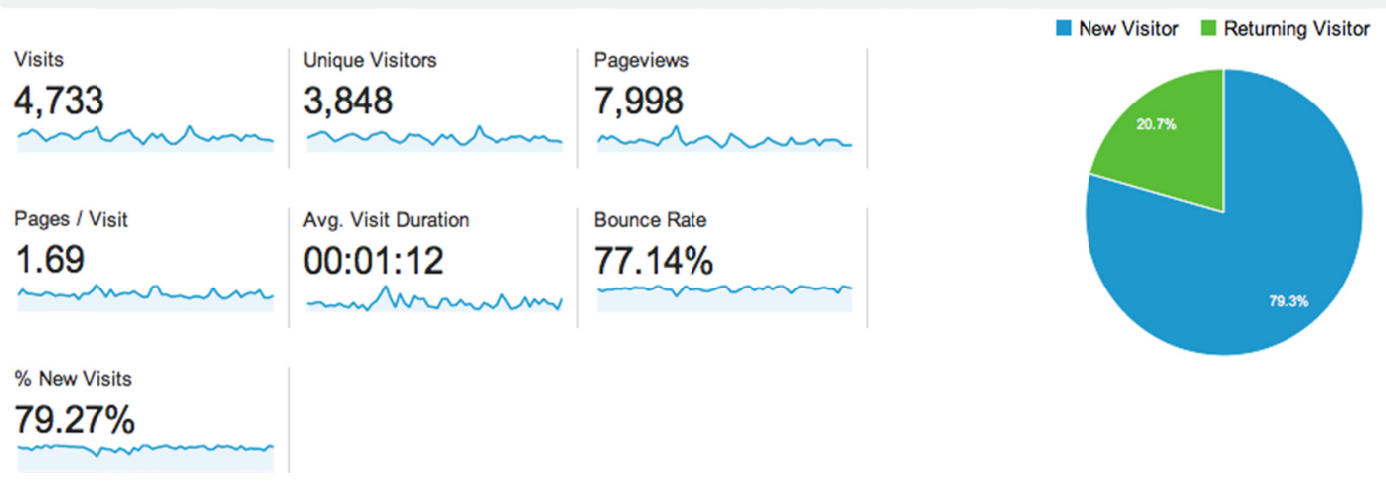

Figure 2. Feb. 24- Apr. 20, 2013 Period 1

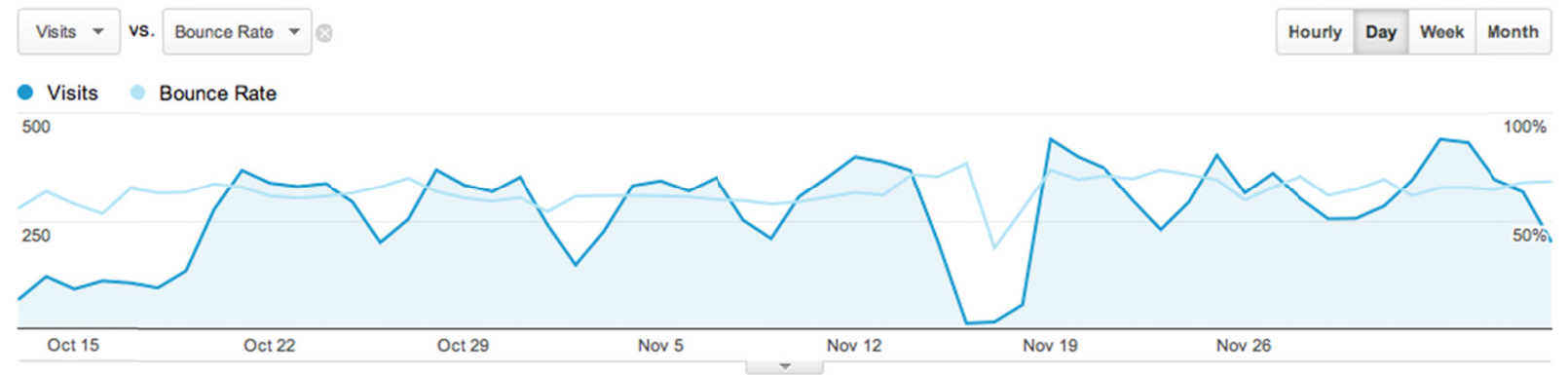

12,684 people visited this site
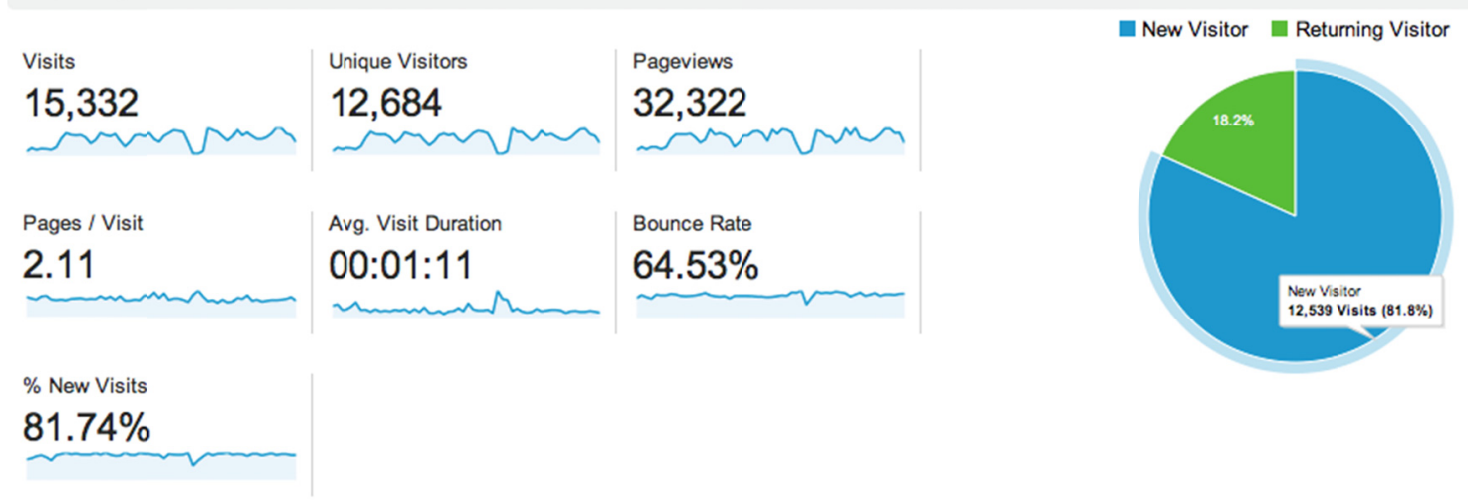

Figure 3. Oct 13- Dec. 7, 2013 Period 2 


\section{Conclusion}

\subsection{Content, Simplicity and Consistency Are the Key}

As a group, Team Web has grown together, working through numerous glitches in order to produce the best possible learning platform and database. Evolving through these changes each team member has learned the importance of consistency and simplicity. The analytical data, before the changes made in summer 2013, compared to the data after the changes demonstrate that these lesson have paid off for the web site.

For Team Web the first step in this learning process was when it finally understood that there must be a consistent link between the ads, keywords, and the content for the site. When executed correctly the team realized that this linkage lowers the bounce rate and increases the amount of time a user stays on the web site. This led the team to the conclusion that a constant linkage results in visits by people who actually want to use the site and as a result stay on the site for longer periods of time.

In addition, the team learned that the site content must be dynamic. It is imperative to keep the webpages updated with original information. Team Web has worked to ensure that it is providing concise content with clear current examples. The analytics show that this effort improves the desired outcomes for the site. In addition, adding different types of learning formats such as the step- by- step YouTube videos has made the arbitration site more interactive and engaging for the user.

\subsection{The Benefits of a Small Group Project with a Real World Purpose}

"Tell me and I forget. Teach me and I remember. Involve me and I learn."

\section{Benjamin Franklin}

Through the use of web provided tools, the members of Team Web have made the web their school and a school for others around the world. In the process they have learned lessons far beyond what any textbook can teach. Through technology their goals were realized and put into actions. Using the analytics, each member was able to observe that through hard work they, with the assistance of their team members, have the ability to provide more than they imagined possible. Lead by one professor, Team Web has become a single unit unified by a similar goal. No member is more important than another and each member is needed in order to reach their main purpose of teaching the world through technology. Collaborating as a group has given each member a chance to showcase their strengths and come to terms with their weaknesses. More importantly each member has learned that in a group project such as Team Web everyone is a student and everyone is a teacher.

This project also has broad implications for any business or institution that has a web presence. It offers an example of how a group web project, not a single web developer, allows each team member to learn more about the product and introduce different perspectives to the website. (Note 51)

\section{References}

Alecu, I. (2011). Personality and learning styles. Economics, Management and Financial Markets, 6(1), $1096-1103$. Retrieved from http://search.proquest.com.ezproxy.gvsu.edu/docview/869529857?accountid=39473

Benjamin, P. (2013). Assessing South Africa's Commission for Conciliation, Mediation and Arbitration (CCMA). International Labour Office: Geneva. Working Paper, 47. Retrieved from https://docs.google.com/viewer?url=http\%3A\%2F\%2Fwww.ilo.org\%2Fpublic\%2Flibdoc $\% 2$ Filo\%2F $2013 \% 2 \mathrm{~F}$ 113B09_102_engl.pdf

Circuit City Stores, Inc. v. Saint Clair Adams, No. 99-1379, 2001 WL 273205 (March 21, 2001)

Elkouri, \& Elkouri. How Arbitration Works $\left(7^{\text {th }}\right.$ ed.). Bloomber Books. Retrieved from http://www.bna.com/elkouri-elkouri-arbitration-p17179870255/

Faber, H.S., \& Katz, H. (1980). Interest Arbitration, Outcomes, and the Incentive to Bargain. 33 Indus \& Lab. Rel. Rev. 55.

Fleming, N.D. (1995). I'm different; not dumb. Modes of presentation (VARK) in the tertiary classroom. In Zelmer, A., (Ed.), Research and Development in Higher Education, Proceedings of the 1995 Annual Conference of the Higher Education and Research Development Society of Australasia (HERDSA), 18, 308-313.

Hoffman, D.A. (2011). Mediation and the Art of Shuttle Diplomacy. Negotiation Journal, 27(3), 263-309. Retrieved from http://onlinelibrary.wiley.com/doi/10.1111/j.1571-9979.2011.00309.x/abstract

Main, M.H. (2013). Two Models of Interest Arbitration. Ohio State Journal of Dispute Resolution, 28(1). 
Taza, Philippe. (n.d.) Bounce rates in higher ed: the good, the bad and the ugly. EDUniverse. Retrieved from $\mathrm{http} / / /$ eduniverse.org/bounce-rates-higher-ed-good-bad-and-ugly

Useem, Jerry. (2014). Business School, Disrupted. The New York Times. Retrieved from http://www.nytimes.com/2014/06/01/business/business-school-disrupted.html

\section{Notes}

Note 1. Adwords are the text advertisements that appear at the top of a Google search result page.

Note 2. More about Google Ad Grants- AdWords for nonprofits can be found here http://www.google.com/grants/

Note 3. http://www.dropbox.com

Note 4. http://www.ooVoo.com

Note 5. The Digital Workplace website provides content dealing with how technology impacts rules in the workplace and laws in the United States. We will not be discussing this website in detail in this paper but it is a major part of the work produced by Team Web GVSU. www.gvsu.edu/e-hr/

Note 6. http://www.negotiation/

Note 7. The arbitration app provides information about arbitration in an easy to use manner. It features video examples and key definitions relating to the arbitration process. This app was also developed by Team Web. https://play.google.com/store/apps/details?id=com.humnlaw.arb

Note 8. Hoffman, David, "Mediation and the Art of Shuttle Diplomacy," Negotiation Journal, July 2011.

Note 9. To see an example of a mediation settlement agreement go to http://www.gvsu.edu/arbitration/michigan-mediation-8.htm

Note 10. To see more information about the arbitration process go to: How arbitration works, Elkouri \& Elkouri: How Arbitration Works, Seventh Bdition. Bloomber Books, http://www.bna.com/elkouri-elkouri-arbitration-p17179870255/

Note 11. To see more information about these three types of arbitration go to http://www.gvsu.edu/arbitration/definitions-67.htm.

Note 12. In Michigan Act 312 deals with interest arbitration between police and fire employees. This prevents them from taking measures like striking which would place the public's well-being at risk. To see a broader discussion of interest arbitration go see: Faber, H.S. \& Katz, H. (1980). Interest Arbitration, Outcomes, and the Incentive to Bargain. 33 Indus \& Lab. Rel. Rev. 5; and Two Models of interest Arbitration, Martin H. Main, Ohio State Journal of Dispute Resolution, Vol 28, No 1, 2013. (2013)

Note 13. Circuit City Stores, Inc. v. Saint Clair Adams, No. 99-1379, 2001 WL 273205 (March 21, 2001).

Note 14. To see the explanation of the arbitration process in detail on the website go to http://www.gvsu.edu/arbitration/the-arbitration-process-48.htm

Note 15. Assessing South Africa's commission for Conciliation, Mediation and Arbitration (CCMA), Benjamin, Paul, Haroon Bhorat \& Kalie Pauw \& Liberty Mncube, 2009. Working Papers 09137, University of Cape Town, Development Policy Research Unit. Haroon Bhorat \& Kalie Pauw \& Liberty Mncube, 2009. "Understanding the Efficiency and Effectiveness of the Dispute Resolution System in South Africa: An Analysis of CCMA Data," Working Papers 09137, University of Cape Town, Development Policy Research Unit. https://docs.google.com/viewer?url=http\%3A\%2F\%2Fwww.ilo.org\%2Fpublic\%2Flibdoc\%2Filo\%2F2013\%2F113B 09_102_engl.pdf

Note 16. The way that people are gathering and processing information is known as a learning style, these often correspond with individuals personalities and natural tendencies. Alecu, I. (2011). PERSONALITYAND LEARNING STYLES. Economics, Management and Financial Markets, 6(1), 1096-1103. Retrieved from http://search.proquest.com.ezproxy.gvsu.edu/docview/869529857?accountid=39473

Note 17. Alecu, I. (2011). PERSONALITYAND LEARNING STYLES. Economics, Management and Financial Markets, 6(1), 1096-1103. from http://search.proquest.com.ezproxy.gvsu.edu/docview/869529857?accountid=39473

Note 18. The VARK model was developed in 1987 by Neil Fleming to classify four different learning styles and how they best respond to different materials. 
Note 19. Fleming, N.D; (1995), I'm different; not dumb. Modes of presentation (VARK) in the tertiary classroom, in Zelmer,A., (ed.) Research and Development in Higher Education, Proceedings of the 1995 Annual Conference of the Higher Education and Research Development Society of Australasia (HERDSA),HERDSA, Volume 18, pp. 308 - 313

Note 20. To see an example of a web site chart go to http://www.gvsu.edu/arbitration/the-arbitration-process-48.htm Note 21. To see an example of the web site videos made by Team Web GVSU go to http://www.gvsu.edu/arbitration/videos-76.htm

Note 22. To see an example of large amount of text on the site go to http://www.gvsu.edu/arbitration/defintions-67.htm

Note 23. To see an example of instructions for students who are preparing to actually try a mock arbitration go to https://docs.google.com/viewer?url=http\%3A\%2F\%2Fwww.gvsu.edu\%2Fcms3\%2Fassets\%2FA710F777-E74C-F8B D-F645CFB2BE41D80C\%2FStudent_Arbitration\%2Fhow_to_handle_an_arbitration_like_a_pro_for_student_only. pdf

Note 24. It should be noted that the Google Analytics did not tell the team how to improve the web site but it did allow the team to see how quickly users left certain pages and these numbers forced the team to think: a. Why are they leaving the page; and $\mathrm{b}$. How can we improve the page to make it more engaging. The analytics also displayed pages that attracted large numbers and showed when users stayed on these pages for longer periods of time. This of course was also a learning tool for the web team.

Note 25. Visit http://www.google.com/grants/ to learn more about Google Grants.

Note 26. https://www.google.com/grants/details.html

Note 27. Google Pro Status increases funding from $\$ 10,000$ to $\$ 40,000$, it is granted to groups who apply after experiencing high traffic with the initial Google grant. https://www.google.com/grants/details.html (Please note that Google is not currently accepting additional applications for the Google Grants Pro status.)

Note 28. In November 2012, the arbitration site received 4,434 visits.

Note 29. The key terms provided here are the tools and resources that GVSU Team Web uses most.

Note 30. To see an example of AdWords refer to this web page: http://www.google.com/adwords/how-it-works/ads-on-google.html?channel=bliss\&utm_medium=ha\&utm_campaig n=us-en-ha-awx02031b 31943880485\&utm_source=awx\&sourceid=awo\&subid=us-en-ha-aw02031b 3194388048 5

Note 31. To see an example of how to create an Ad Campaign refer to this web page: https://support.google.com/adwords/answer/1704395?hl=en

Note 32. To learn more about Ad Groups visit: https://support.google.com/adwords/answer/6298?hl=en

Note 33. To learn more about impressions visit: https://support.google.com/adwords/answer/6320?hl=en

Note 34. To learn more about what accounts for a click visit: https://support.google.com/adwords/answer/31799?hl=en

Note 35. To learn more about Cost per Click visit: https://support.google.com/adwords/answer/116495?hl=en

Note 36. To learn more about Click Through Rate visit https://support.google.com/adwords/answer/2615875?hl=en

Note 37. https://support.google.com/adwords/topic/3121777?hl=en\&ref_topic=3119071

Note 38. To see an fuller explanation of visit duration refer to this web page: https://support.google.com/analytics/answer/1006253?hl=en

Note 39. To see a fuller definition of keywords refer to this webpage: https://support.google.com/adwords/answer/6323?hl=en\&ref_topic $=24936$

Note 40. To see a fuller explanation of in page Analytics visit https://support.google.com/analytics/answer/2558811?hl=en

Note 41. The bounce rate was high and avg. visit duration was low. This means that people were accessing the websites but often times leaving instantly. Both of these numbers are averages, and outliers can highly affect the data. 
Note 42. Prior to July 2013, GVSU Team Web used one Ad Campaign for all of their AdGroups. With a stronger focus on site interaction they broke down there AdWords account into multiple campaigns, two for each website and one for each app. The campaigns were then broken down in AdGroups. Each AdGroup targeted a specific topic within the website. The websites were given two mirrored campaigns, except one targeted the United States, while the other targeted the rest of the world.

Note 43. Each campaign was allocated a certain percentage of the grant, allowing for each portion of the website to get a more equal showing. Prior this change "hot topic" ads were the ones getting the most clicks, often times the "hot topic" ads resulted in the highest bounce rates and lowest visit durations.

Note 44. After talking to Google Advisors, team web learned the importance of tailoring their keywords, learning that tailored keywords result in the ads more accurately supporting the user's search.

Note 45. Team Web learned that each ad must be specific to the portion of the website that they are linked to. This lowers the number of unintentional visits.

Note 46. GVSU Team Web created You Tube videos that provide examples of each step in the arbitration process.

Note 47 . The two 8 week periods in the same year were chosen to give a comparison of before and after the changes. The $\$ 40.000$ grant was in use during each period.

Note 48. Oct. 13 thru Dec 7, 2013 and Feb 24 through Apr. 20. 3013

Note 49. Taza, Philippe. (n.d.) Bounce rates in higher ed: the good, the bad and the ugly. EDUniverse. Retrieved from http://eduniverse.org/bounce-rates-higher-ed-good-bad-and-ugly

Note 50. This bounce rate goal was made after discussions with persons from Google who had experience with monitoring many commercial web sites.

Note 51. To view interviews of Team Web GVSU that was shown at the East Coast Google Education Summit please go to: https://www.youtube.com/watch?v=mhgJ6SuS124 